\title{
The TMS 2009 Annual Meeting: A Professional Highlight of the Year
}

\author{
Ray Peterson
}

By the time you read this note the TMS 2009 Annual Meeting in San

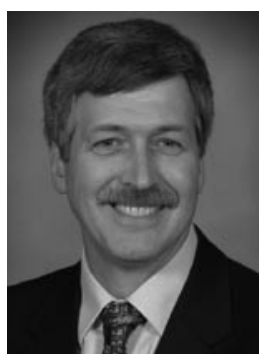
Francisco will be just a rosy memory for most of us. Despite a challenging economic environment, the meeting was well attended and successful. Almost 3,700 people attended the meeting which consisted of 64 symposia. A record 2,600 papers were presented at the meeting and eight books were produced from the presentations. All attendees received a CDROM with all of the published papers available for perusal after the meeting. This assemblage provides a huge savings over buying the books or individual papers after the meeting.

To me several events and activities stood out as great reasons to attend the Annual Meeting. For example, the exhibit had more than 130 companies and organizations available to discuss their latest products and services with our attendees. Where else can you interact with so many of your suppliers in such a short time and in a such personal manner?

In programming, as a member of the Light Metals community, the Aluminum Plenary Session was a very topical event for me. Our industry, like many others, is facing a challenging environment as demand drops and prices fall. Three highly placed corporate leaders and an economist explained the mechanics of the aluminum market today. They also provided their views on where our industry may be headed and challenged us on the critical issues that we as technologists must address to improve our industry and make our company practices more sustainable.
Another program highlight, the Acta Materialia Distinguished Lecture Series, was held on Sunday afternoon rather than during normal technical session programming. This allowed me to attend for the first time and I found it to be a very informative event. How often do you get a chance to listen in person to a recognized technical leader in material science?

At the awards banquet, we recognized outstanding colleagues for their technological accomplishments and service to our profession. In particular, we recognized five new Fellows (William W. Gerberich, Douglas A. Granger, Michael K. Miller, Tresa M. Pollock, and Hong Yong Sohn) for their technical contributions. We also recognized Milton Wadsworth, a former president of both TMS and our Founding Society, AIME, with the AIME Honorary Member Award.

I had the pleasure of announcing the new Vittorio de Nora Prize. This prize was created to recognize outstanding materials science R\&D contributions to the reduction of environmental impacts, particularly greenhouse gas emissions, as applied in global metallurgical industries. The generous annual prize is funded through an endowment from the de Nora family. Vittorio de Nora was a pioneer in materials processing and one of the great Italian technologists of the 20th century. The award is aimed at materials scientists and engineers under the age of 40 who have made research contributions to technologies that have a global impact. I am eagerly awaiting the first nominations for this award, which will be accepted until June 30, 2009.

In actions directly related to our members, your Board agreed to hold the Society dues constant for 2010 , cre- ated a Women in Materials Science and Engineering Committee as a subcommittee of the Membership and Student Development Committee, approved applications for membership for 53 new candidates, and formed an ad hoc committee to address the process and promotion of TMS honors and awards.

The enthusiasm level of our student members was refreshing. You would think the outcome of the Alcoa Materials Bowl was life or death based on how seriously the participants were behaving. The tension was palpable during the final round between Boise State University and Colorado School of Mines. Additionally, the Student Poster Session, with more than 50 presenters showed through the quality of the presentations and the work performed that our universities are doing a fantastic job of preparing the future leaders in our field. Finally, 15 of the students were recipients of TMS scholarships.

Forty-five TMS volunteers participated in a community service project at Alemany Farm. The farm is an organic, low-impact garden nestled on a small plot of land in an urban environment. Our participants planted various organic vegetables to accompany an existing garden that provides food and income to nearby low-income residents. The volunteers also weeded garden beds and spread mulch.

As always the TMS Annual Meeting was one of the professional highlights of the year for me as I hope it was for you. I look forward to seeing you next year in Seattle where we plan to provide our members with an Annual Meeting of even greater value and impact to their professional careers.

Ray Peterson is a Technology Director at Aleris International, Rockwood, Tennessee, and the 2009 TMS President. 